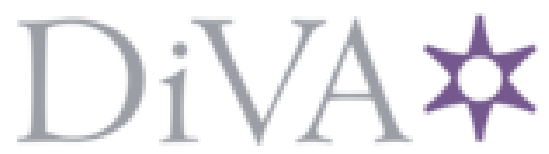

http://www.diva-portal.org

This is the published version of a paper published in Optical Materials Express.

Citation for the original published paper (version of record):

Rydberg, S., Engholm, M. (2013)

Charge transfer processes and UV induced absorption in Yb:YAG single crystal laser materials.

Optical Materials Express, 113(22): Art. no. 223510

http://dx.doi.org/10.1063/1.4810858

Access to the published version may require subscription.

N.B. When citing this work, cite the original published paper.

Permanent link to this version:

http://urn.kb.se/resolve?urn=urn:nbn:se:miun:diva- 18685 


\section{AIP Appilied Physics}

Charge transfer processes and ultraviolet induced absorption in Yb:YAG single crystal laser materials

S. Rydberg and M. Engholm

Citation: J. Appl. Phys. 113, 223510 (2013); doi: 10.1063/1.4810858

View online: http://dx.doi.org/10.1063/1.4810858

View Table of Contents: http://jap.aip.org/resource/1/JAPIAU/v113/i22

Published by the AIP Publishing LLC.

Additional information on J. Appl. Phys.

Journal Homepage: http://jap.aip.org/

Journal Information: http://jap.aip.org/about/about_the_journal

Top downloads: http://jap.aip.org/features/most_downloaded

Information for Authors: http://jap.aip.org/authors

\section{ADVERTISEMENT}

\section{Instruments for advanced science}
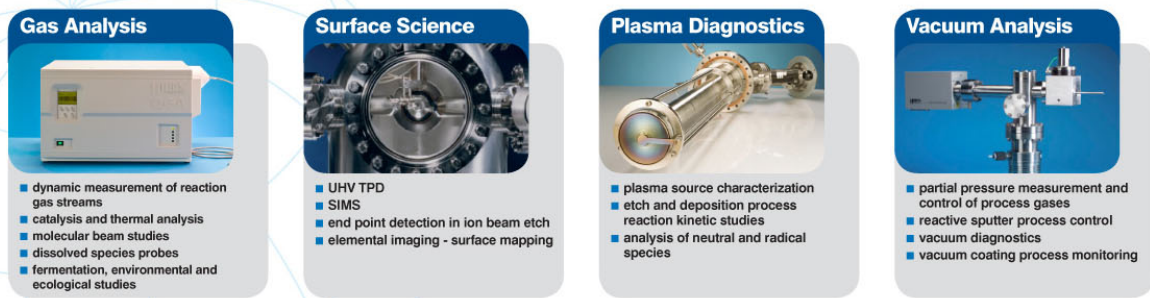

contact Hiden Analytical for further

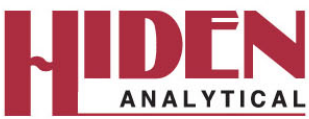

info@hideninc.com www.HidenAnalytical.com CLICK to view our product catalogue 


\title{
Charge transfer processes and ultraviolet induced absorption in Yb:YAG single crystal laser materials
}

\author{
S. Rydberg and M. Engholm ${ }^{\text {a) }}$ \\ Department of Information, Technology and Media, Physical Electronics and Photonics, Mid-Sweden \\ University, SE-851 70 Sundsvall, Sweden
}

(Received 20 April 2013; accepted 28 May 2013; published online 14 June 2013)

\begin{abstract}
Charge transfer (CT) transitions and UV induced color centers in Yb:YAG single crystals have been investigated. A simultaneous pair formation of a stable $\mathrm{Yb}^{2+}$ ion and a hole related $\left(\mathrm{O}^{-}\right)$ color center (hole polaron) are observed through a CT-process. Slightly different types of hole related color centers are formed in Yb:YAG crystals containing small levels of iron impurities. Furthermore, excitation spectroscopy on the UV irradiated Yb:YAG samples could confirm an energy transfer process between $\mathrm{Yb}^{3+}$ and $\mathrm{Yb}^{2+}$ ions. The findings are important for an increased knowledge of the physical loss mechanisms observed in Yb-doped laser materials, such as the nonlinear decay process in Yb:YAG crystals as well as the photodarkening phenomenon in Yb-doped fiber lasers. (C) 2013 AIP Publishing LLC. [http://dx.doi.org/10.1063/1.4810858]
\end{abstract}

\section{INTRODUCTION}

Rare earth (RE) metals are commonly used as dopants in different solid state laser materials. Ytterbium $(\mathrm{Yb})$ has gained an enormous success, over the last few decades, as an active laser ion in both crystalline and glass materials due to its simple energy level structure, low quantum defect, and broad emission spectrum in the $1 \mu \mathrm{m}$ range. The use of ytterbium doped solid state laser materials in various applications has been boosted by the rapid development of high power diode lasers suitable for pumping. Yb:YAG thin-disc lasers have been shown to be an efficient alternative to the conventional flash lamp and diode pumped Nd:YAG lasers and are being increasingly used in demanding industrial applications. However, the ever increasing interest for higher output powers and new application areas places high demands on the laser gain material.

For example, a nonlinear decay process with an increased heat generation which depends on the absorbed pump power has been reported for Yb:YAG crystals. ${ }^{1}$ This nonlinear decay process sets a limit for the maximum $\mathrm{Yb}$ doping concentration in Yb:YAG single crystals to about $12 \% .^{2} \mathrm{Yb}: \mathrm{YAG}$ is one of the most commonly used crystals in high power thin-disc lasers and a higher $\mathrm{Yb}$-doping concentration would be desirable, as the discs could be made thinner in order to minimize thermal effects.

In Yb-doped silica fiber lasers, there is the well known phenomenon of Photodarkening (PD), which introduces optical losses and reduces the output power over time. ${ }^{3}$ The PD phenomenon has involved extensive research over the last decade and several routes have been suggested to improve, or even prevent the degradation of the gain material. ${ }^{4-6}$ However, there is an ongoing discussion concerning the physical mechanisms responsible for PD in fiber lasers. ${ }^{7,8}$ The physical mechanism behind the observed nonlinear decay in Yb:YAG is also not fully understood, although, tremendous progress has been made over the last few years.

${ }^{a)}$ Electronic mail: Magnus.Engholm@miun.se
Interestingly, there are many similarities between the PD phenomenon observed in fiber lasers and the nonlinear decay process in $\mathrm{Yb}$ :YAG single crystals. This is particularly true, as both loss mechanisms show a very strong dependence on the Yb-doping concentration and the density of excited $\mathrm{Yb}$ ions. Hence, it is not unlikely that both loss mechanisms are related and that they share a common physical origin. It has been suggested that the change of valence state for the $\mathrm{Yb}$-ion plays a major role for both the PD process $^{10}$ and for the nonlinear decay process. ${ }^{11}$ The $\mathrm{Yb}$-ion is known to be multivalent in many host materials, which, under intense irradiation, also could initiate charge transport resulting in color center formation and heat generation. So far, however, no clear evidence has, to the best of our knowledge, been reported for the formation of divalent ytterbium in YAG crystals through a charge transfer (CT) process.

The objective of this work is to investigate the CT processes related to the $\mathrm{Yb}$ ion in $\mathrm{Yb}: \mathrm{YAG}$ single crystals and the formation of UV induced color centers through excitation to the CT-absorption band. A CT transition involves an interaction between the $\mathrm{Yb}^{3+}$ ion and the host lattice and corresponds to the transfer of an electron from a nearby oxygen ligand to the $\mathrm{Yb}$ ion according to the relation

$$
Y b^{3+}+h \nu_{C T} \rightarrow Y b^{2+}+h_{\text {temp } / \text { bound }},
$$

where $\mathrm{h} \nu_{C T}$ represents the excitation energy to the different $\mathrm{CT}$ states and $\mathrm{h}_{\text {temp } / \text { bound }}$ corresponds to a temporarily formed or a bound hole, which is left behind on the oxygen ligand. CT transitions are observed for several rare-earth (RE) ions and corresponds to the transfer of an electron from the highest occupied orbitals of the valence band in the host lattice, e.g., from the $2 p$ orbitals of oxygen in the case of oxygen based hosts, to the RE-ion. CT transitions are usually observed as strong and broad absorption bands in the UVrange as they are not restricted by any selection rules. There have been many publications over the last few decades reporting on $\mathrm{CT}$ transitions of RE ions in different crystalline host materials, for example, the extensive work made by 
Dorenbos. ${ }^{12}$ However, it is not until quite recently that CTprocesses were observed to have a major influence on different loss processes in $\mathrm{Yb}$ doped high power lasers. ${ }^{4,9,10}$

The motivation in relation to this work is to gain further understanding for different loss processes in Yb-doped laser materials in general and Yb-doped fiber lasers in particular. The choice to study CT processes in Yb:YAG single crystals is because the interpretation and analysis of CT processes and radiation induced color centers in a crystalline material is less complex when compared to that for amorphous silica glass. Despite the considerable amount of work published over the last 50 years on radiation induced defects and color centers in various RE-doped YAG crystals, see, e.g., Refs. 13 and 14, surprisingly, the nature and origin in relation to many of these color centers are still not fully understood. Hence, further studies are required and we believe that this work will provide a deeper understanding for the $\mathrm{CT}$ processes in Yb-doped laser materials in general and also contribute to a deeper understanding of the physical mechanisms related to PD in Yb-doped fiber lasers.

\section{EXPERIMENTAL}

A summary of all investigated YAG crystals are listed in Table I. We have limited our investigation to Yb:YAG crystals with relatively low Yb-concentration. This will ensure that the CT absorption band in the UV spectral range can be resolved accurately. We expect, however, that CT processes observed for Yb:YAG crystals with relatively low $\mathrm{Yb}$ concentration will also hold for the higher concentration levels used in Yb:YAG disc lasers. The YAG samples have been grown by the Institute of Laser Physics (ILP) at the University of Hamburg by using the Czochralski growth technique. Depending on the crucible material used in the growth process of the Yb:YAG single crystals, a certain amount of impurities are usually unavoidable. One of the most commonly used crucible materials is iridium, however, crystals grown by using this crucible material typically show relatively high levels of $\mathrm{Fe}$ - and Ni-impurities. ${ }^{15}$ On the other hand, it has been observed that YAG crystals grown from rhenium crucibles contain much lower levels of $\mathrm{Fe}$ and Ni impurities. ${ }^{15}$ As the majority of YAG crystals will generally contain small (tens of ppm) but not insignificant amounts of impurities (e.g., Fe), our investigation will also cover the influence of iron impurities on different $\mathrm{CT}$ processes in Yb:YAG crystals. A comparison will be made between different UV-irradiated Yb:YAG crystals grown from both iridium and rhenium crucibles. Unless otherwise stated, all the crystals have been annealed in an oxidizing atmosphere $\left(>1000^{\circ} \mathrm{C}\right)$ prior to any irradiation experiments.

TABLE I. Investigated YAG samples.

\begin{tabular}{lcc}
\hline \hline YAG sample & Yb conc. [at. \%] & Crucible material \\
\hline A & - & Iridium \\
B & 0.20 & Iridium \\
C & 0.10 & Iridium \\
D & 0.10 & Rhenium \\
\hline \hline
\end{tabular}

Therefore, the number of oxygen vacancies that unavoidably appear during the growth process is expected to be low.

Absorbance measurements are made with a combined halogen and deuterium light source. An Ocean Optics USB $2000+$ spectrometer is used for transmission measurements in the UV/V is spectral range and the Maya2000 Pro for the Vacuum UV spectral range. For the irradiation experiments, a laser driven light source (LDLS) from Energetiq is used coupled to a monochromator set to $210 \mathrm{~nm}$ and focused onto the sample. The intensity of the irradiation was of the order of $\sim 0.1 \mathrm{~mW}$ with a spectral distribution of $\sim 10 \mathrm{~nm}$ (FWHM). The choice of $210 \mathrm{~nm}$ is based on its good overlap with the $\mathrm{CT}$ absorption band of the $\mathrm{Yb}^{3+}$ ion in YAG. This ensures that no direct host lattice transitions occurs, which could form additional color centers and make the interpretation more complicated. The absorption coefficient is calculated as

$$
A(\lambda)=-\frac{1}{d} \ln \left(\frac{I(\lambda)}{I_{0}(\lambda)}\right),
$$

where $d$ is the sample thickness and $I$ and $I_{0}$ are the transmitted intensity and the light source intensity, respectively.

The absorption coefficient is measured before and after treatment (irradiation or annealing) and the differential absorption is calculated as the difference between the spectra measured before and after treatment. One sample, the 0.2 at. \% Yb:YAG sample B has also been post processed in a reducing atmosphere consisting of $\mathrm{N}_{2} / \mathrm{H}_{2}(95 \% / 5 \%)$ for $20 \mathrm{~h}$ at $1050^{\circ} \mathrm{C}$.

\section{RESULTS AND DISCUSSION}

Figure 1 shows the absorption spectrum for the $\mathrm{Yb}: \mathrm{YAG}$ sample $B$ in the UV spectral range before the $\mathrm{N}_{2} / \mathrm{H}_{2}$ annealing. The band, centered at $198 \mathrm{~nm}$ close to the absorption edge, is the CT absorption band of the $\mathrm{Yb}^{3+}$ in YAG. The spectral position of the $\mathrm{CT}$ absorption band varies for different host materials and depends on, e.g., covalency, coordination number, and the $\mathrm{Yb}^{3+}$-anion separation. ${ }^{16} \mathrm{~A} \mathrm{CT}$

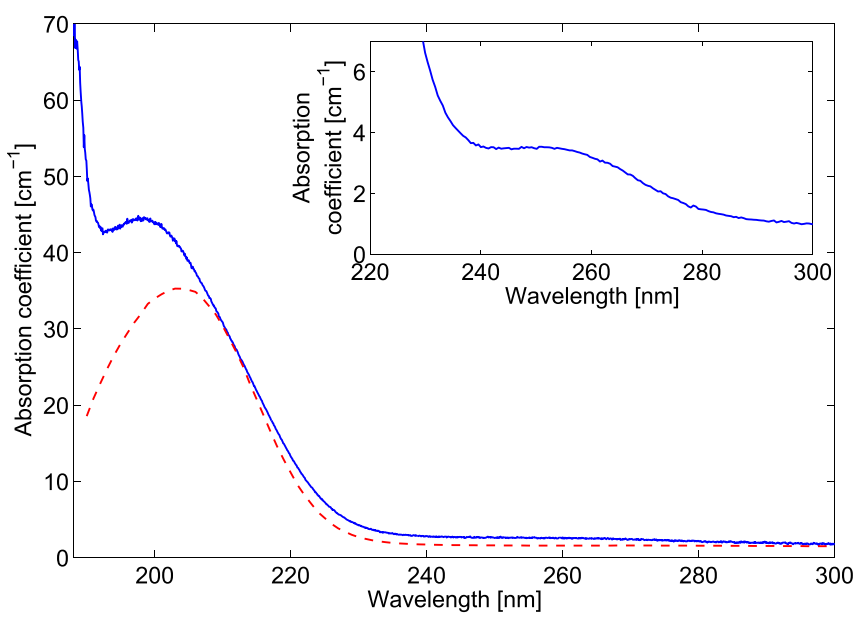

FIG. 1. Absorption spectrum of sample B, 0.2\% Yb:YAG showing the CT absorption band around $200 \mathrm{~nm}$ (blue solid line). The red dashed line shows the excitation spectrum monitored for the $4 f-4 f$ transition near $1 \mu \mathrm{m}$. Small impurity levels of iron are commonly observed in Yb:YAG crystals and the small band at $255 \mathrm{~nm}$ is associated with a CT transition of $\mathrm{Fe}^{3+}$ (inset). 
transition corresponds to the transfer of an electron from an oxygen ligand to the $\mathrm{Yb}^{3+}$-ion and will cause a temporal or permanent change in the valence state for the $\mathrm{Yb}$-ion together with a localized or delocalized hole on a nearby oxygen ligand. CT-luminescence with two bands centered at $330 \mathrm{~nm}$ and $500 \mathrm{~nm}$ together with $f-f$ luminescence near $1 \mu \mathrm{m}$ is observed upon recombination. ${ }^{17}$ In addition to the strong CT band, a small band centered at $255 \mathrm{~nm}$ is observed, see inset of Fig. 1. This band has been identified at an earlier stage as a CT transition between $\mathrm{Fe}^{3+}$ ions and the oxygen ligands, see, e.g., Chen et al. ${ }^{13}$ and is commonly observed in YAG crystals grown in iridium crucibles. Iron is known to substitute aluminum in the YAG lattice and Chen et al. ${ }^{13}$ showed with Electron Paramagnetic Resonance (EPR) spectroscopy that the $255 \mathrm{~nm}$ CT band is a composite of CT transitions involving $\mathrm{Fe}^{3+}$ ions occupying both octahedral and tetrahedral sites. The $255 \mathrm{~nm}$ band is not found in the absorption spectrum of the rhenium grown Yb:YAG crystal D (not shown). The presence of $\mathrm{Fe}^{3+}$ impurities in the iridium grown $\mathrm{Yb}$ :YAG crystal is also verified by means of photoluminescence measurements, see Fig. 2. The $800 \mathrm{~nm}$ luminescence has been identified as the ${ }^{4} T_{1}\left({ }^{4} G\right) \rightarrow{ }^{6} A_{1}$ transition of $\mathrm{Fe}^{3+}$ in the tetrahedral site of YAG. ${ }^{18}$ The $800 \mathrm{~nm}$ luminescence is also observed in the iridium grown non-Yb-doped YAG sample A (not shown) but, not in the rhenium grown Yb:YAG sample D, which confirms the absence of Fe-impurities in this sample. Also included in Fig. 1 is the excitation spectrum monitored at $1 \mu \mathrm{m}$ which shows a good correlation with the $\mathrm{CT}$ absorption band. The excitation band maximum is slightly shifted to longer wavelengths as compared with the absorption band maximum at $198 \mathrm{~nm}$, which suggests the existence of more CT sub-bands as also found in, e.g., Yb/Al doped silica glass. ${ }^{4}$

Figure 3 shows the differential absorption spectrum for the $\mathrm{N}_{2} / \mathrm{H}_{2}$ post-processed reference sample B. Primarily, three additional absorption bands centered around $280 \mathrm{~nm}$, $390 \mathrm{~nm}$, and $660 \mathrm{~nm}$ are observed. These are commonly assigned to $4 f^{14}-4 f^{13} 5 d$ transitions of the $\mathrm{Yb}^{2+}$ ion; see, e.g., Refs. 15 and 19 although other interpretations have been reported. ${ }^{20} \mathrm{~A}$ deeper analysis of the observed

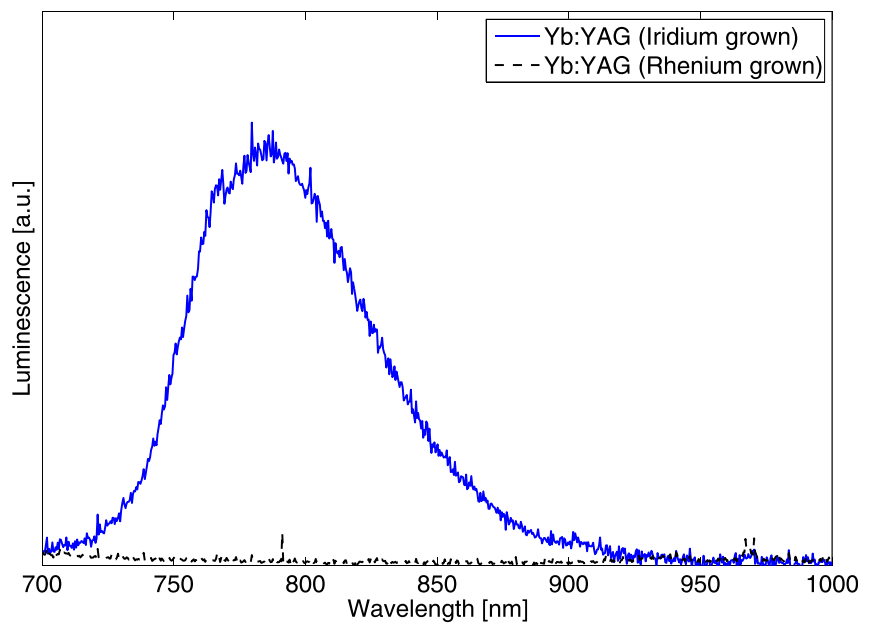

FIG. 2. Photo-luminescence of Yb:YAG sample $\mathrm{C}$ grown in iridium crucible (blue solid line) and Yb:YAG sample D grown in rhenium crucible (black dashed line). The excitation wavelength is $250 \mathrm{~nm}$.

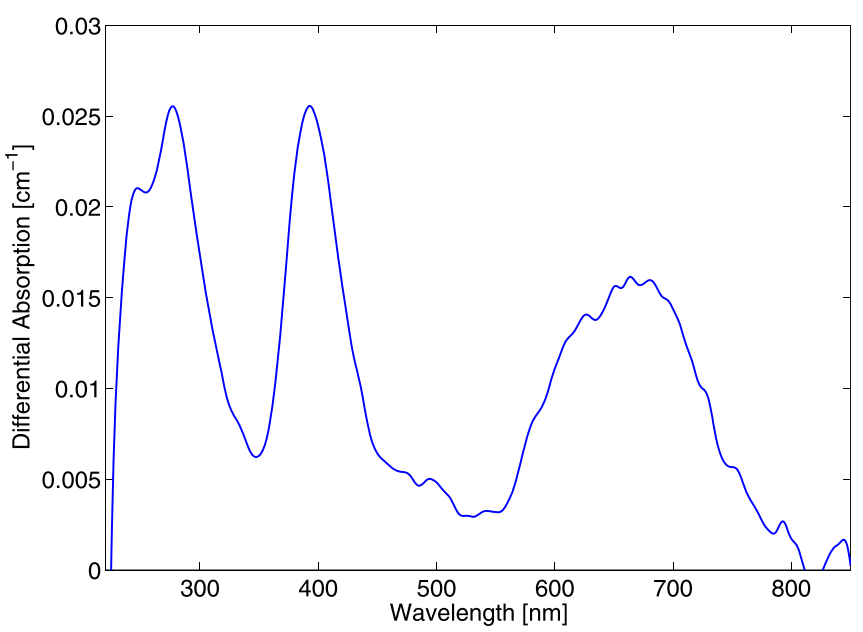

FIG. 3. Differential absorption spectrum of the 0.2 at. \% Yb:YAG annealed in $\mathrm{N}_{2} / \mathrm{H}_{2}$ atmosphere showing additional absorption bands at $280 \mathrm{~nm}$, $390 \mathrm{~nm}$, and $660 \mathrm{~nm}$ assigned to $4 f^{14}-4 f^{13} 5 d$ transitions of the $\mathrm{Yb}^{2+}$ ion.

absorption bands and an attempt to assign the bands to different $4 f^{14}-4 f^{13} 5 d$ transitions of the $\mathrm{Yb}^{2+}$ ion is beyond the scope of this work. Hence, we agree with previous authors that it is very likely that the observed absorption bands at $280 \mathrm{~nm}, 390 \mathrm{~nm}$, and $660 \mathrm{~nm}$ originate from inter configurational transitions of the $\mathrm{Yb}^{2+}$ ion.

In as-grown $\mathrm{Yb}$ :YAG crystals, the $\mathrm{Yb}^{2+}$ ions have been shown to be stabilized by $\mathrm{F}^{+}$color centers (oxygen vacancy with a trapped electron) due to the large number of oxygen vacancies formed during the growth process. In the $\mathrm{N}_{2} / \mathrm{H}_{2}$ post-processed sample $\mathrm{B}$, the expectation is that the majority of the formed $\mathrm{Yb}^{2+}$ ions will be stabilized by interstitial hydrogen, $\mathrm{H}^{+}$forming $\mathrm{OHO}^{3-}$ or $\mathrm{OH}^{-}$complexes. ${ }^{21}$ The hydrogen complexes show absorption bands in the infrared and not in the UV- and visible spectral range. Therefore, the differential spectrum in Fig. 3 is assumed to solely originate from the inter configurational transitions of the $\mathrm{Yb}^{2+}$ ion.

\section{A. UV irradiation experiments}

\section{UV irradiation of rhenium grown Yb:YAG}

UV irradiation experiments have been made on the Yb:YAG samples C (iridium grown) and D (rhenium grown). The UV irradiated rhenium grown Yb:YAG sample $\mathrm{D}$ shows an induced absorption ranging from deep UV across the visible range as displayed in Fig. 4. At first glance, it shows a clear resemblance with the absorption spectrum of the $\mathrm{N}_{2} / \mathrm{H}_{2}$ annealed sample $\mathrm{B}$, see Fig. 5. The similar bands around $390 \mathrm{~nm}$ and $660 \mathrm{~nm}$ offer a first indication of the presence of $\mathrm{Yb}^{2+}$-ions. In addition, a broad absorption band is observed near $300 \mathrm{~nm}$, which partly conceals an expected $\mathrm{Yb}^{2+}$ related band at $280 \mathrm{~nm}$. To further analyze the origin of the induced absorption bands, the $\mathrm{Yb}^{2+}$ associated spectrum in Fig. 3 was normalized to the $660 \mathrm{~nm}$ band in the differential absorption spectrum in Fig. 5 and subtracted. The result is a single broad band centered at $300 \mathrm{~nm}$, see Fig. 5. To maintain charge neutrality in the Yb:YAG lattice and for the $\mathrm{Yb}^{2+}$ ions to be stable, a pair generation is necessary in the CT process. This indicates that the broad band observed 


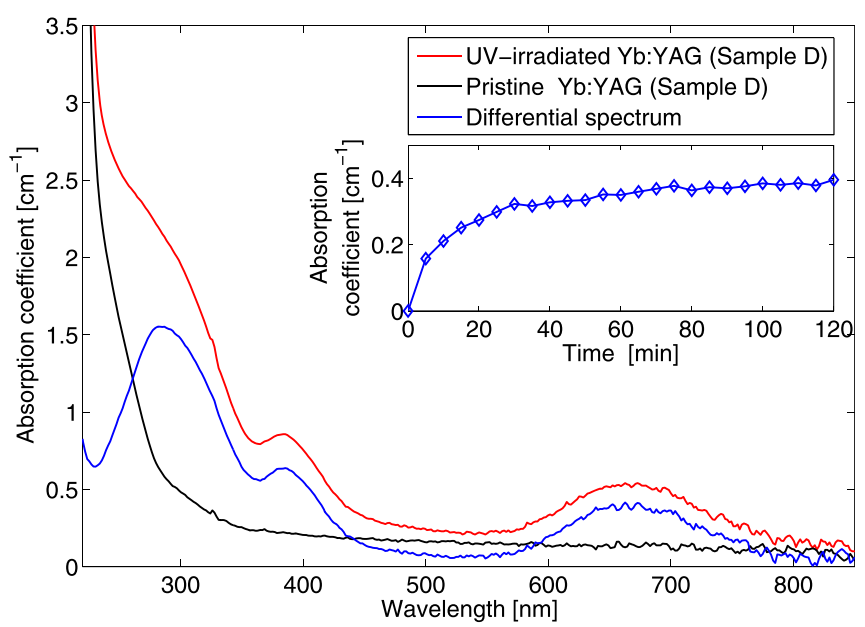

FIG. 4. Induced absorption for the irradiated Yb:YAG (0.1 at. \%) sample D (rhenium grown). The induced loss rate for the $660 \mathrm{~nm}$ band is displayed in the inset.

near $300 \mathrm{~nm}$ must be associated with some hole related color center that can charge compensate the formed $\mathrm{Yb}^{2+}$ ions. Possible charge compensating color centers that can stabilize the $\mathrm{Yb}^{2+}$ ion in YAG are $\mathrm{F}^{+}$color centers or an oxygen atom with a missing electron, i.e., an $\mathrm{O}^{-}$center. $\mathrm{F}^{+}$centers in YAG crystals with oxygen vacancies are known to have absorption bands around $235 \mathrm{~nm}$ and $370 \mathrm{~nm} .^{22}$ These centers, on the other hand, are completely eliminated when the YAG crystals are annealed in air. As our samples were annealed in air prior to the irradiation experiments, oxygen vacancies are not expected. Hence, charge compensation is unlikely to be made by $\mathrm{F}^{+}$centers, which leaves us with the second alternative, namely the formation of a stable $\mathrm{O}^{-}$hole center. The nature of this hole centre can most likely be referred to as a bound hole polaron. ${ }^{23}$ An electron transfer to the $\mathrm{Yb}$-ion through the $\mathrm{CT}$ process will cause an outward displacement of the surrounding anions. The hole left behind may then be trapped in a (self-induced) potential well.

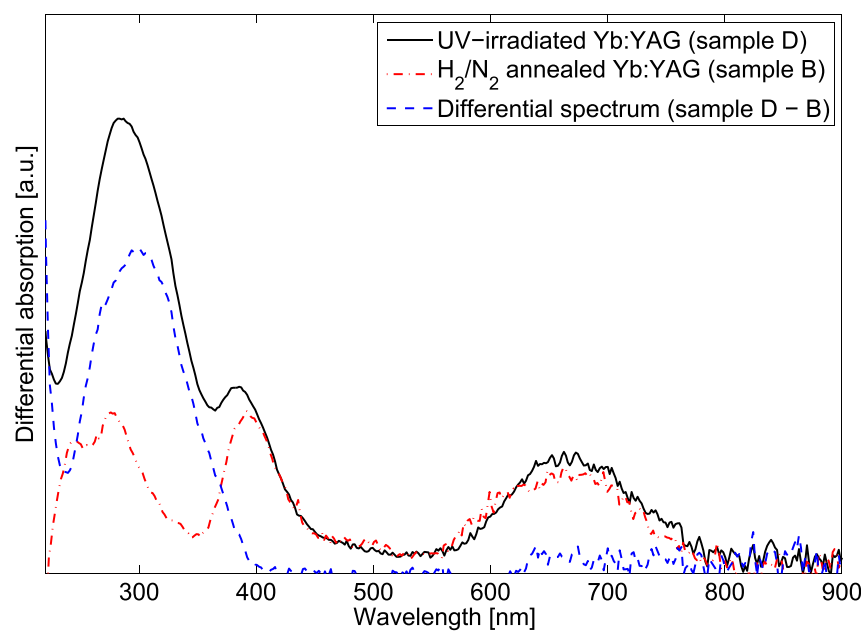

FIG. 5. Differential absorption spectrum for the irradiated rhenium grown Yb:YAG (0.1 at. \%) sample D (black solid line) and the post annealed $\mathrm{N}_{2} / \mathrm{H}_{2}$ sample B (red dashed-dotted line). The dashed blue line shows the differential spectrum between the UV-irradiated sample D and the post annealed sample B.
Electronic transitions within this potential well can give rise to optical absorption peaks. The number of publications reporting on polarons and $\mathrm{O}^{-}$hole centers in $\mathrm{Yb}$ :YAG crystals is very limited and hence we have been unsuccessful in finding a good match for the $300 \mathrm{~nm}$ band in the literature. Our results, however, clearly show the formation of $\mathrm{Yb}^{2+}$ ions in the CT process and this surely favors the interpretation that the broad band centered around $300 \mathrm{~nm}$ is associated with $\mathrm{O}^{-}$color centers and is most likely to be bound hole polarons rather than $\mathrm{F}^{+}$color centers.

\section{UV irradiation of iridium grown Yb:YAG}

Similar features are observed for the UV-irradiated iridium grown $\mathrm{Yb}$ :YAG sample $\mathrm{C}$, which contains small amounts of iron impurities, see Fig. 6. The $\mathrm{Yb}^{2+}$ associated bands at 280,390, and $660 \mathrm{~nm}$ are also apparent in this sample but the most striking difference is a much broader superimposed spectrum ranging from deep UV to the NIR range. In addition, the induced loss rate appears to be slower in comparison with the rhenium grown sample. Following the same procedure as for sample D, Fig. 7 shows the differential UV induced spectrum for sample $\mathrm{C}$ in which the associated $\mathrm{Yb}^{2+}$ spectrum has been subtracted. The resulting differential spectrum shows a broad induced absorption across the UV- and visible range, which cannot be assigned to a single color center. Apart from the band around $350 \mathrm{~nm}$ and a small band near $250 \mathrm{~nm}$, the differential spectrum is likely to consist of a superposition of absorption bands from several color centers.

By comparing the results from the irradiated samples $\mathrm{C}$ and $\mathrm{D}$, it becomes clear that the observed differences should be attributed to the small amount (tens of ppm) of iron impurities in sample D. Iron ions are known to substitute aluminum in both octahedral and tetrahedral sites in YAG. Hence, it is not unreasonable to assume that the $\mathrm{Fe}^{3+}$ (or $\mathrm{Fe}^{2+}$ ) impurity ions will influence the YAG lattice in such a way that it gives rise to several types of bound polarons. The self-induced potential wells will then be different depending on the type of cation ( $\mathrm{Al}$ or $\mathrm{Fe}$ ) in the tetrahedral or

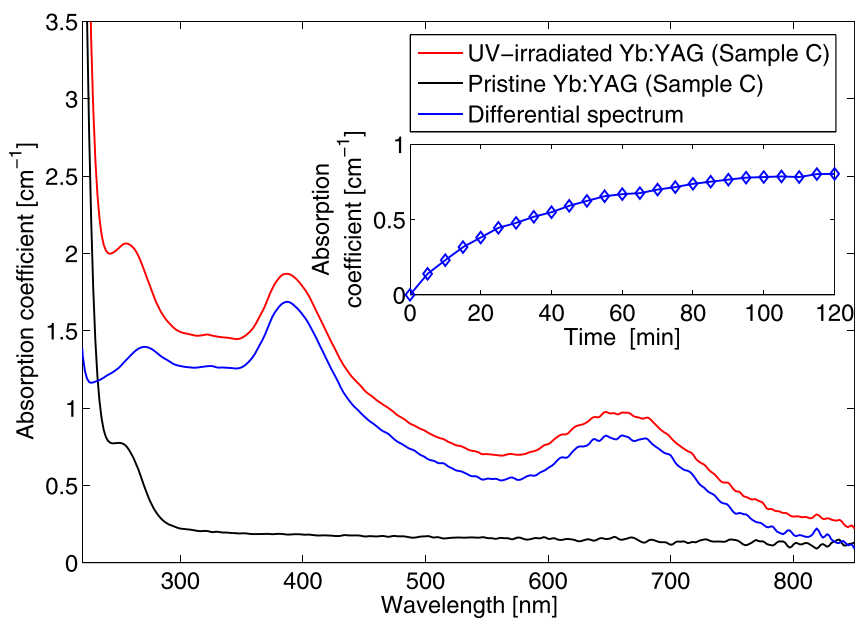

FIG. 6. Induced absorption for the irradiated Yb:YAG (0.1 at. \%) sample C (iridium grown). The induced loss rate for the $660 \mathrm{~nm}$ band is displayed in the inset. 


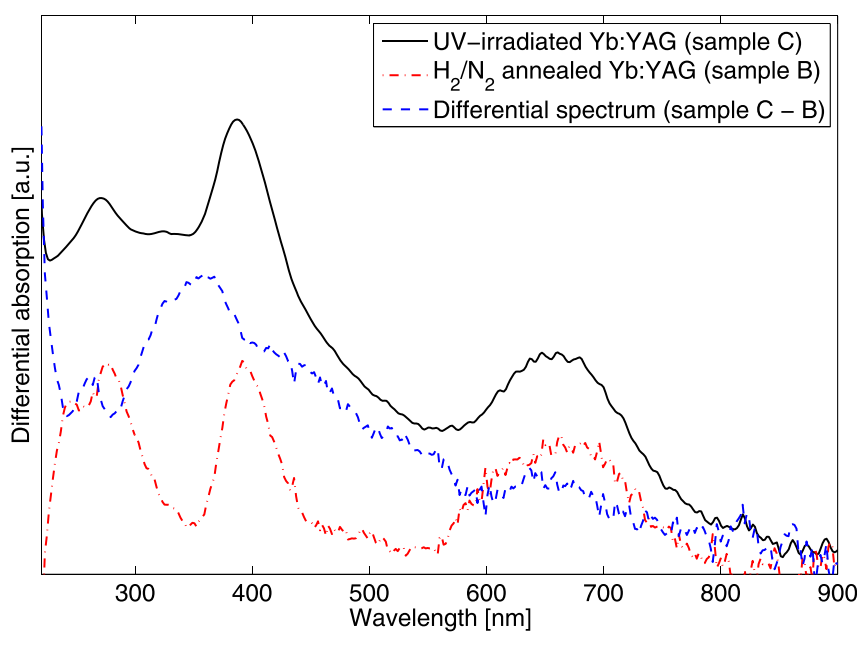

FIG. 7. Differential absorption spectrum for the irradiated iridium grown Yb:YAG (0.1 at. \%) sample C (black solid line) and the post annealed $\mathrm{N}_{2} / \mathrm{H}_{2}$ sample B (red dashed-dotted line). The dashed blue line shows the differential spectrum between the UV-irradiated sample $\mathrm{C}$ and the post annealed sample B.

octahedral site. Hence, the electronic transitions within these potential wells could result in many different overlapping absorption bands in the UV and the visible spectral range. It is quite surprising, however, that the small amount of iron is able to have such a large influence on the induced optical losses. This is particularly true considering that there is only one $\mathrm{Fe}^{3+}$ ion per $50-100 \mathrm{Yb}$ ions in the iridium grown Yb:YAG sample D.

\section{B. Energy transfer between $\mathrm{Yb}$ ions of mixed valence}

It has been suggested that the presence of $\mathrm{Yb}^{2+}$ can play a major role within the nonlinear decay processes in $\mathrm{Yb}$ :YAG crystals $^{15}$ as well as for the PD process in $\mathrm{Yb}$-doped fiber lasers. $^{24}$ In particular, energy transfer between $\mathrm{Yb}^{3+}$ and $\mathrm{Yb}^{2+}$ ions has been suggested as a possible route for the observed loss mechanisms. However, no experimental evidence has, to the best of our knowledge, been presented for such an energy transfer. In addition to the excitation measurements made on the pristine Yb:YAG samples, we also performed excitation spectroscopy on the Yb:YAG samples after the UV irradiation experiments. Figure 8 shows the excitation spectrum on samples $\mathrm{C}$ and D monitored at $1 \mu \mathrm{m}$. In addition to the main excitation band shown earlier in Fig. 1, two additional excitation bands are observed for the irradiated samples $\mathrm{C}$ and $\mathrm{D}$. Interestingly, these two excitation bands show a good correlation with the $\mathrm{Yb}^{2+}$ related bands at $280 \mathrm{~nm}$ and $390 \mathrm{~nm}$, observed in the differential absorption spectrum of the $\mathrm{N}_{2} / \mathrm{H}_{2}$ annealed sample $\mathrm{B}$. Based on these measurements, it is evident that an energy transfer process is present between $\mathrm{Yb}^{2+}$ and $\mathrm{Yb}^{3+}$ ions. This is most likely to occur between two closely spaced $\mathrm{Yb}^{2+}$ and $\mathrm{Yb}^{3+}$ ions, e.g., in an oxygen linkage $\left(\mathrm{Yb}^{2+}-\mathrm{O}-\mathrm{Yb}^{3+}\right)$ in the $\mathrm{YAG}$ crystal. Interestingly, we did not observe any excitation band near $660 \mathrm{~nm}$ (not shown), which might have been expected. This could indicate that energy transfer is only possible from the higher lying $4 f-5 d$ states or, that the $660 \mathrm{~nm}$ band does indeed not correspond to an inter configurational transition.

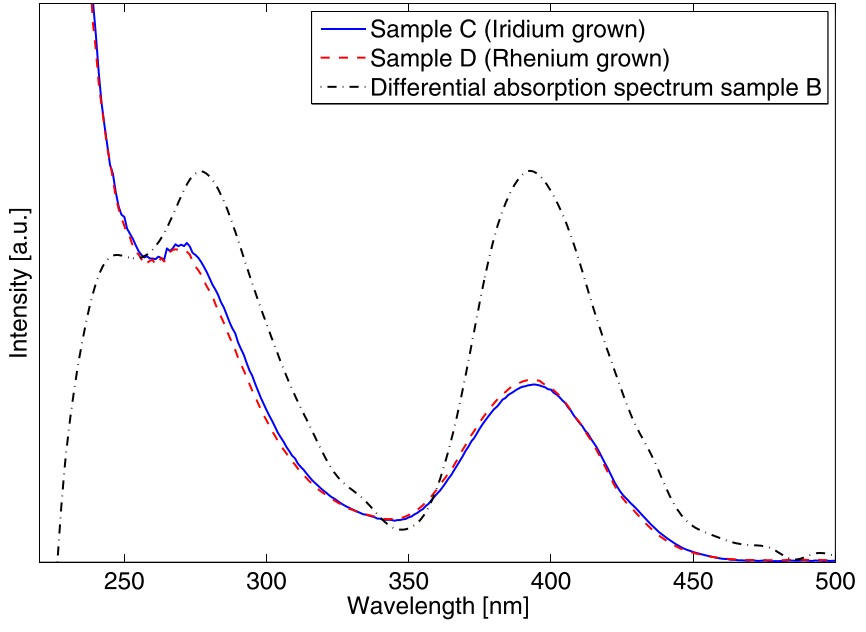

FIG. 8. Excitation spectra monitored for the $4 f-4 f$ transition near 1 um measured on the UV-irradiated Yb:YAG samples C (blue solid line) and D (red dashed line). A good correlation is observed with the differential absorption spectrum of the $\mathrm{N}_{2} / \mathrm{H}_{2}$ annealed sample $\mathrm{B}$.

The later could instead favour the interpretation made by Zakharko et $a l .{ }^{20}$ that the $660 \mathrm{~nm}$ band corresponds to an inter valence charge transfer transition between $\mathrm{Yb}^{2+}$ and $\mathrm{Yb}^{3+}$ ions.

\section{CONCLUSIONS}

To summarize, we have shown that long term irradiation to the CT absorption band centered near $200 \mathrm{~nm}$ in Yb:YAG will cause a pair generation of stable $\mathrm{Yb}^{2+}$ ions together with $\mathrm{O}^{-}$color centers, which is able to, most likely, be attributed to bound hole polarons. The complexity is further increased for samples containing small amounts of iron impurities, which will generate additional color centers with broad absorption bands in the UV- and visible spectral range. We were also able to verify an energy transfer process between $\mathrm{Yb}^{2+}$ and $\mathrm{Yb}^{3+}$ ions in irradiated $\mathrm{Yb}$ :YAG single crystals by means of excitation spectroscopy on irradiated Yb:YAG samples.

The observations are important and will contribute to an increased knowledge in relation to the physical origin of the loss mechanisms in Yb-doped laser materials. This is particularly true when considering the PD-phenomenon in Yb-doped silica fiber lasers for our present investigation on the Yb:YAG single crystals which did indeed show that divalent $\mathrm{Yb}$-ions can form upon excitation to the CT absorption band. Recent results made on $\mathrm{Yb} / \mathrm{Al}$ doped silica preforms and fibers also show that divalent $\mathrm{Yb}$-ions are formed in the PD-process. ${ }^{25}$

\section{ACKNOWLEDGMENTS}

Professor Günther Huber and Dr. Klaus Petermann at the Institute of Laser Physics, University of Hamburg are gratefully acknowledged for providing the Yb:YAG samples for this investigation. The Swedish Agency for Economic and Regional Growth, Fiber Optic Valley, The County Administrative Board in Västernorrland, and the Regional Development Council of Gävleborg are gratefully acknowledged for the financial support. 
${ }^{1}$ M. Larionov, K. Schuhmann, J. Speiser, C. Stolzenburg, and A. Giesen, "Nonlinear Decay of the Excited State in Yb:YAG," in Advanced SolidState Photonics, Technical Digest (Optical Society of America, 2005), paper TuB49. Available at http://www.opticsinfobase.org/abstract.cfm? URI=ASSP-2005-TuB49

${ }^{2}$ C. Brandt, S. T. Fredrich-Thornton, K. Petermann, and G. Huber, "Photoconductivity in Yb-doped oxides at high excitation densities," Appl. Phys. B 102, 765-768 (2011).

${ }^{3}$ J. Koponen, M. Söderlund, H. Hoffman, D. Kliner, and J. Koplow, "Photodarkening measurements in large mode area fibers," Proc. SPIE 6453, 64531E (2007).

${ }^{4}$ M. Engholm and L. Norin, "Preventing photodarkening in ytterbiumdoped high power fiber lasers; correlation to the UV-transparency of the core glass," Opt. Express 16, 1260-1268 (2008).

${ }^{5} \mathrm{M}$. Engholm, P. Jelger, F. Laurell, and L. Norin, "Improved photodarkening resistivity in Yb-doped fiber lasers by Cerium co-doping," Opt. Lett. 34, 1285-1287 (2009).

${ }^{6} \mathrm{~S}$. Jetschke, M. Leich, S. Unger, A. Schwuchow, and J. Kirchhof, "Influence of Tm- or Er-codoping on the photodarkening kinetics in $\mathrm{Yb}$ fibers," Opt. Express 19, 14473-14478 (2011).

${ }^{7} \mathrm{M}$. Engholm and L. Norin, "Comment on "photodarkening in Yb-doped aluminosilicate fibers induced by $488 \mathrm{~nm}$ irradiation"," Opt. Lett. 33, 1216 (2008).

${ }^{8}$ S. Yoo, C. Basu, A. Boyland, C. Sones, J. Nilsson, J. Sahu, and D. Payne, "Photodarkening in Yb-doped aluminosilicate fibers induced by $488 \mathrm{~nm}$ irradiation," Opt. Lett. 32, 1626-1628 (2007).

${ }^{9} \mathrm{~S}$. T. Fredrich-Thornton, "Nonlinear losses in single crystalline and ceramic Yb:YAG thin-disk lasers," Ph.D. thesis (der Universität Hamburg, 2010).

${ }^{10}$ M. Engholm, L. Norin, and D. Åberg, "Strong UV-absorption and visible luminescence in ytterbium-doped aluminosilicate glass under UV-excitation," Opt. Lett. 32, 3352-3354 (2007).

${ }^{11}$ S. T. Fredrich-Thornton, J.-F. Bisson, D. Kouznetsov, K. Ichi Ueda, K. Petermann, and G. Huber, "Up-conversion to the conduction band in highly doped $\mathrm{Yb}: \mathrm{YAG}$ and $\mathrm{Yb}: \mathrm{Y}_{2} \mathrm{O}_{3}$ and its effect on thin-disk lasers," in Conference on Lasers and Electro-Optics/Quantum Electronics and Laser Science Conference and Photonic Applications Systems Technologies (Optical Society of America, 2007), p. CFJ6.

${ }^{12} \mathrm{P}$. Dorenbos, "Systematic behaviour in trivalent lanthanide charge transfer energies," J. Phys. Condens. Matter 15, 8417-8434 (2003).
${ }^{13}$ C. Y. Chen, G. J. Pogatshnik, Y. Chen, and M. R. Kokta, "Optical and electron paramagnetic resonance studies of $\mathrm{Fe}$ impurities in yttrium aluminum garnet crystals," Phys. Rev. B 38, 8555-8561 (1988).

${ }^{14}$ Y. Dong, J. Xu, G. Zhou, G. Zhao, L. Su, X. Xu, H. Li, J. Si, X. Qian, $\mathrm{X}$. Li, and J. Shen, "Color centers in Yb:YAG crystals grown by temperature-gradient techniques," Phys. Status Solidi A 203, 2496-2500 (2006).

${ }^{15}$ D. Fagundes-Peters, N. Martynyuk, K. Lunstedt, V. Peters, K. Petermann, G. Huber, S. Basun, V. Laguta, and A. Hofstaetter, "High quantum efficiency YbAG-crystals," J. Lumin. 125, 238-247 (2007).

${ }^{16} \mathrm{G}$. Blasse, "The ultraviolet absorption bands of $\mathrm{Bi}^{3+}$ and $\mathrm{Eu}^{3+}$ in oxides," J. Solid State Chem. 4, 52-54 (1972).

${ }^{17}$ L. van Pieterson, M. Heeroma, E. de Heer, and A. Meijerink, "Charge transfer luminescence of $\mathrm{Yb}^{3+}$," J. Lumin. 91, 177-193 (2000).

${ }^{18}$ V. Lupei, G. Boulon, A. Lupei, M. Elejalde, A. Brenier, and C. Pedrini, "Spectrally selective energy transfer from $\mathrm{Fe}^{3+}$ to $\mathrm{Tm}^{3+}$ in garnet lattices," J. Lumin. 60-61, 237-240 (1994).

${ }^{19}$ M. Henke, J. Persson, and S. Kück, "Preparation and spectroscopy of $\mathrm{Yb}^{2+}$-doped $\mathrm{Y}_{3} \mathrm{Al}_{5} \mathrm{O}_{12}, \mathrm{YAlO}_{3}$ and $\mathrm{LiBaF}_{3}$," J. Lumin. 87-89, 1049-1051 (2000).

${ }^{20}$ Y. M. Zakharko, A. Luchechko, S. Ubizskii, I. Syvorotka, N. Martynyuk, and I. Syvorotka, "The recombination channels of luminescence excitation in YAG:Yb single crystalline films," Radiat. Meas. 42, 843-846 (2007).

${ }^{21}$ D. P. Devor, R. C. Pastor, and L. G. DeShazer, "Hydroxyl impurity effects in YAG," J. Chem. Phys. 81, 4104-4119 (1984).

${ }^{22}$ M. Springis, A. Pujats, and J. Valbis, "Polarization of luminescence of colour centres in YAG crystals," J. Phys. Condens. Matter 3, 5457-5461 (1991).

${ }^{23}$ J. Devreese, "Polarons," in Encyclopedia of Applied Physics (VCH, 1996), Vol. 14, pp. 383-409.

${ }^{24}$ A. A. Rybaltovsky, S. S. Aleshkina, M. E. Likhachev, M. M. Bubnov, A. A. Umnikov, M. V. Yashkov, A. N. Gur'yanov, and E. M. Dianov, "Luminescence and photoinduced absorption in ytterbium-doped optical fibres," Quantum Electron. 41, 1073-1079 (2011).

${ }^{25} \mathrm{~S}$. Rydberg and M. Engholm, "Experimental evidence for the formation of divalent ytterbium in the photodarkening process of $\mathrm{Yb}$-doped fiber lasers," Opt. Express 21, 6681-6688 (2013). 